\title{
Monitoring system of environmental stochastic characteristics and renewable energy units' efficiency in an extreme continental climate
}

\author{
S. E. Shcheklein ${ }^{1}$, Iu. E. Nemikhin ${ }^{1}$, A. I. Popov ${ }^{1} \&$ A. T. Jailany ${ }^{2}$ \\ ${ }^{1}$ Ural Federal University, Russia \\ ${ }^{2}$ Aleksandria University, Egypt
}

\begin{abstract}
While solving renewable energy tasks, problems with the calculation of some statistical changes, important for the development of their structure and practical application, may arise. The following factors are stochastic:

- Energy reception (solar, wind, water resources, etc.);

- Energy consumption (domestic, municipal and industrial areas);

- Changes in ambient temperature.

These factors have a wide time scale, and periodic and random components.

It is obvious that these groups of factors are correlated; the growth of the solar energy reception leads to the increase in temperature and illumination, which in turn reduces the need for heat and electricity consumption.

In order to fulfill the detailed analysis of the correlation between climatic factors and their influence on the efficiency of the existing renewable energy equipment in the UrFU, a high-speed multi-channel monitoring system for climate and energy characteristics has been developed and put into operation. The system includes a distributed network of local devices connected to the central server which collects, accumulates and processes data of more than 100 measured parameters gathered every second.

Based on a long series of observations, the system allowed one to assess renewable energy units' productivity in the conditions of variable ambient temperatures, typical for a region with an extreme continental climate.

Keywords: renewable energy, monitoring system, power supply, solar radiation.
\end{abstract}




\section{Introduction}

The growing interest in renewable energy usage in Russia, associated with the significant potential, typical for the vast territory of the country [1], demands an objective understanding of the technologies' potential in order to achieve the goal functions that are required from any power technology; sufficiency and reliability of energy supply and economic efficiency. Both conservative skepticism and unwarranted optimism of the potential energy consumers hinder the wide adoption of renewable energy. Calculations based on average energy reception rates; disregard for real ambient characteristics variations and energy consumption graphics; misunderstanding of the problems connected with starting currents and power quality; disdain for rules of sanitary safety for hot water supply installations, etc. lead to numerous errors in the practical creation of many energy supply projects [2]. The climatic conditions in many regions of Russia are characterized by an abnormally low ambient temperature during $2 / 3$ of the year. Figure 1 shows comparative data for an HSDD (heating season degree-day) indicator assessment. HSDD is a measurement of energy needed to heat a building up to $20^{\circ} \mathrm{C}$. The analysis shows that the Russian Federation is one of the leaders in the required amount of energy.

The goal of this paper is to analyze the capabilities of renewable energy units operating in severe climate conditions to meet the thermal and electrical energy requirement by means of the developed multi-channel, multi-parameter, highspeed, distributed in space, computer monitoring system [3].

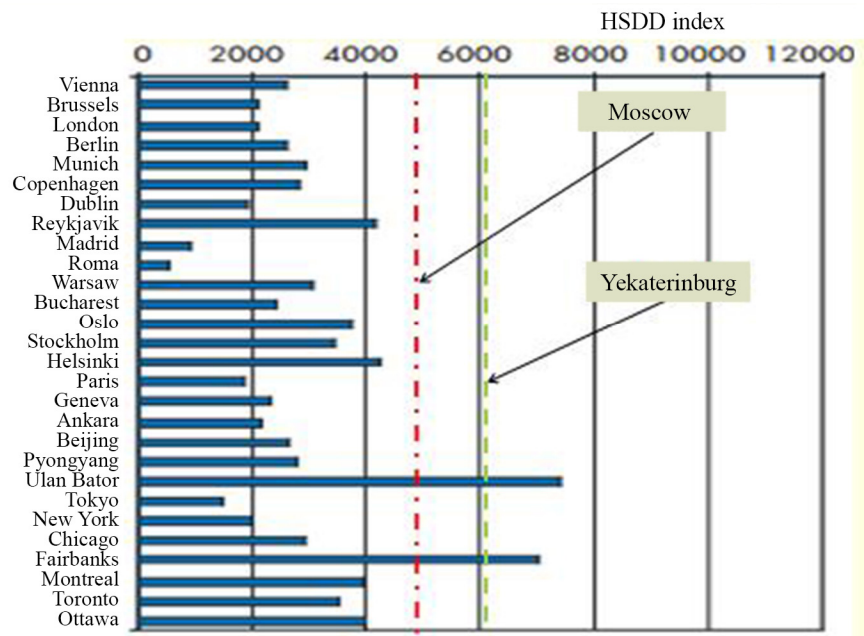

Figure 1: Heating season degree-day index for several world cities. 


\section{System of collecting measurement information}

Characteristics of the collection system of measurement data are shown in table 1.

The system is based on a programmable platform CompactRIO (Compact Reconfigurable Input Output) by National Instruments. It is a multifunctional embedded platform for data collection and management, designed for tasks that require high productivity and reliability [4].

NI CompactRIO is an embedded control and measurement system based on the technology of configurable input/output NI RIO. It consists of a chassis with an embedded programmable logic integrated scheme (PLIS), real-time controller and input/output modules (Fig. 2).

Due to the fact that observed renewable energy plants are located in a wide territory that is not covered with a single fiber-optic network, connection between local measurement complexes and the central platform and server is organized via Wi-Fi channels.

Table 1: System of collecting measurement information.

\begin{tabular}{|l|l|}
\hline Name of the stand & Key used parameters \\
\hline Meteorological complex & - temperature \\
& - humidity \\
& - precipitation \\
& - wind speed \\
& - wind direction \\
& - full solar radiation \\
\hline Photoelectric unit & - output load voltage of the photoelectronic unit \\
& - current \\
\hline Wind power unit & - output load voltage of the wind power unit \\
& - current \\
\hline Solar collector & - input temperature \\
& - output temperature \\
& - coolant rate \\
\hline Solar concentrator & - input temperature \\
& - output temperature \\
& - coolant rate \\
\hline Heat pump unit & - input temperature \\
& - output temperature \\
& - coolant rate \\
\hline Biogas unit & - biomass input temperature \\
& - temperature in the bioreactor \\
& - biogas consumption \\
& - biogas pressure \\
& - pH index in the bioreactor \\
\hline & \\
\hline
\end{tabular}




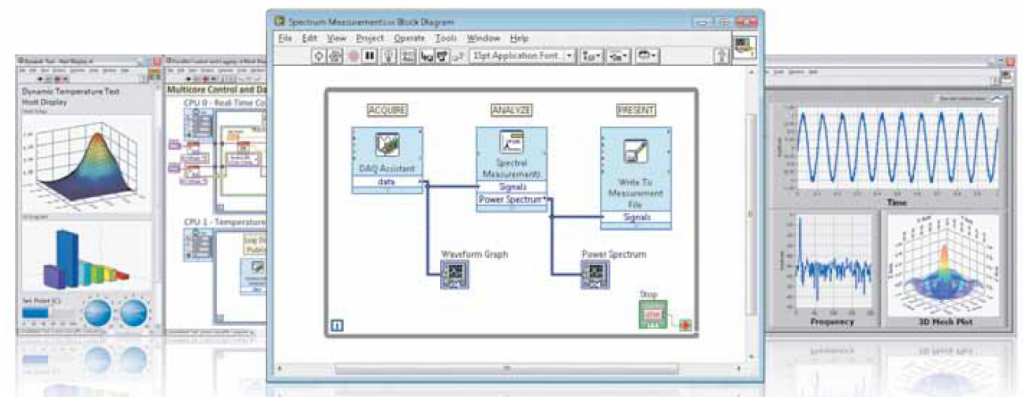

Figure 2: Screen interface of the system.

The system provides the constant collection of information from more than 100 primary transducers and 6 fast-acting video cameras that control the parameters and images of wind power, photoelectric, biogas and other renewable energy research stands in the territory of the UrFU (Fig. 3). It collects and transmits the information via Wi-Fi channels to the server and periphery users' workstations for the following analysis and processing. To provide fast monitoring of the units' characteristics, special processing software was created in LabVIEW.

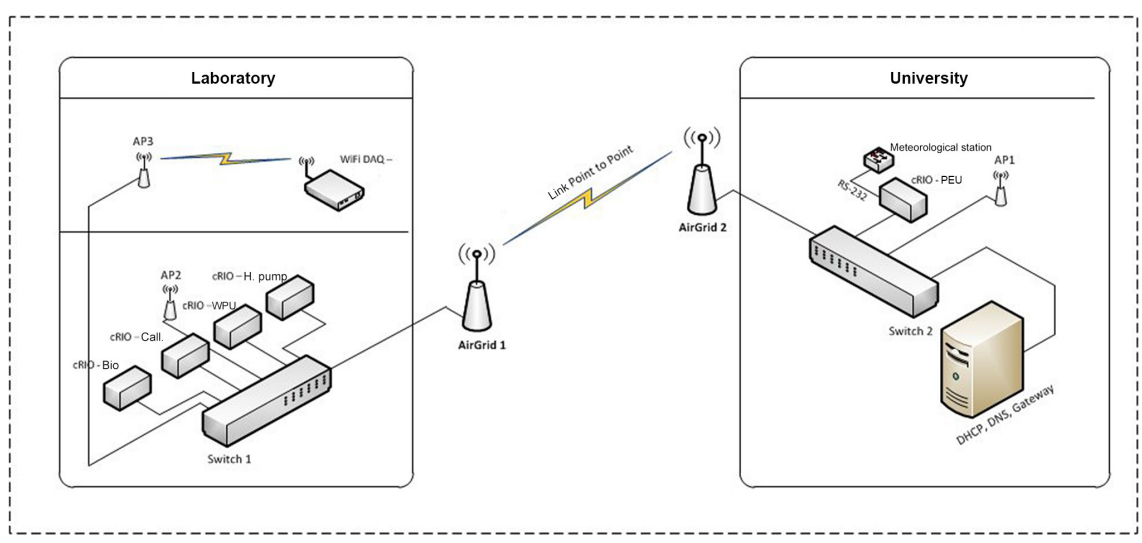

Figure 3: $\quad$ Stands location in the UrFU territory.

Referring to the corresponding unit question-answering system of the interface allows the visualization of specific points and characteristics of the measured parameters in the form of a block measurement diagram (Fig. 4).

The developed monitoring system allows us to form measured data sets with a time interval from 1 second to 1 month, to conduct statistical processing, store the data on the primary measurements and process the results in the pool memory of the server. 


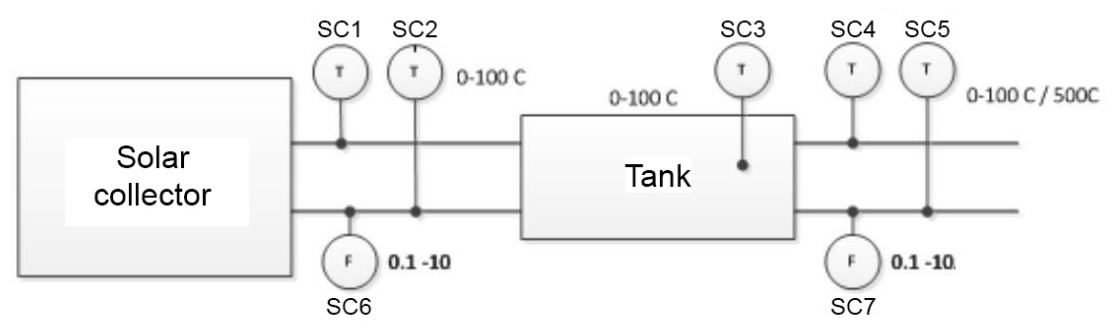

Figure 4: Solar collector measurement points scheme.

\section{Results}

\subsection{Solar radiation}

The data processing results of the solar energy reception over a ten year period (Fig. 5) show statistical stability, preservation of the average values and the nature of solar energy. However, the experimental values are characterized by significant fluctuations due to local climatic factors.

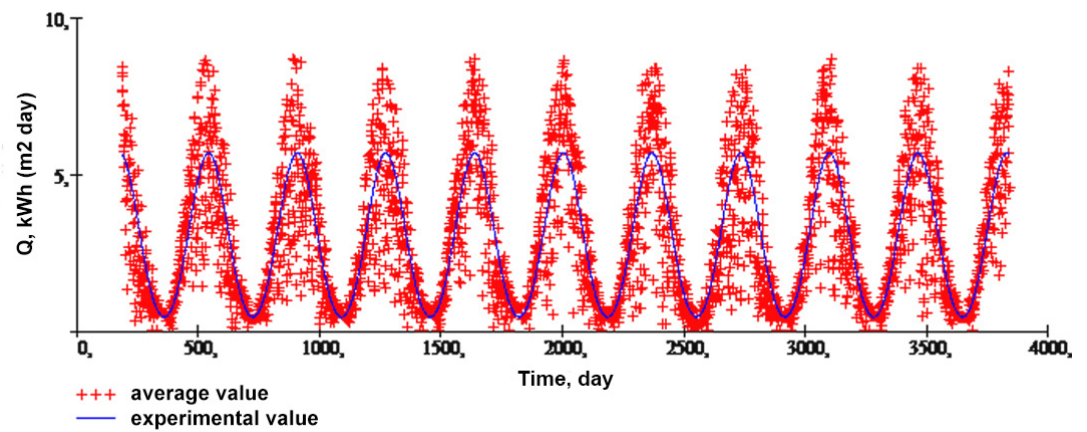

Figure 5: Graph of solar radiation daily sums change (10 year cycle).

The processing of the experimental value for the interval $T_{i}$ was carried out by the formulas:

$$
\begin{gathered}
M_{Q}^{m o n}\left(T_{i}\right)=\int_{-\frac{T_{i}}{2}}^{\frac{T_{i}}{2}} M_{Q}(n) d t \\
\sigma_{Q}^{m o n}\left(T_{i}\right)=\sqrt{\int_{-\frac{T_{i}}{2}}^{\frac{T_{i}}{2}}\left(\sigma_{Q}^{m o n}(n)\right)^{2} d t}
\end{gathered}
$$

where $T_{i}-i$ is a time interval. 
Comparison of the stochastic characteristics evaluation results with long-term meteorological observations data is shown in Fig. 6. Characteristics of the average values and mean-square deviations defined by experimental data array processing are in accord with the data [5], which indicates the reliability of the computer monitoring system measurements.

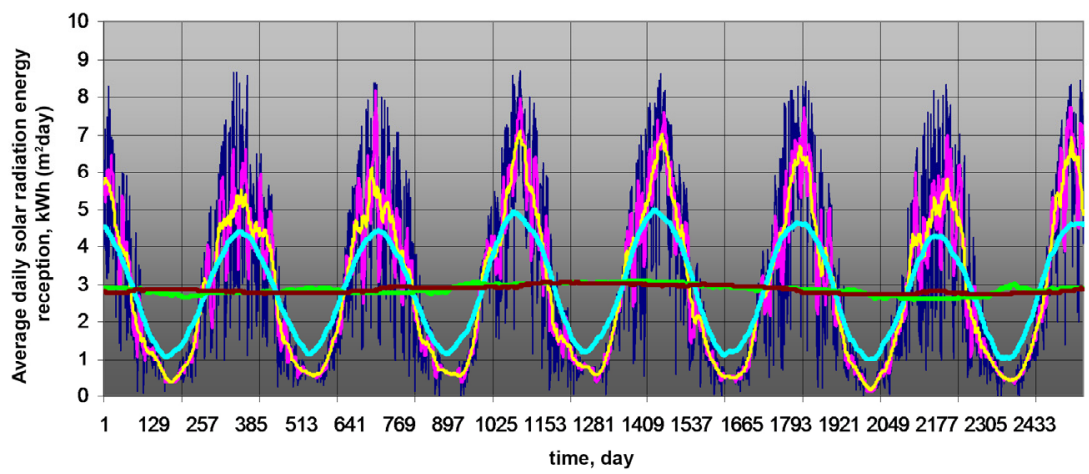

-1 day -7 days -30 days -180 days -365 days -730 days

Figure 6: Graph of solar radiation energy reception change for different average intervals.

It should be noted that the daily solar radiation reception has a distinct stochastic character. Figure 7 shows the specific power of solar radiation reception for a summer month. Figure 8 shows the specific reception of solar energy and electricity generated by "in duration".

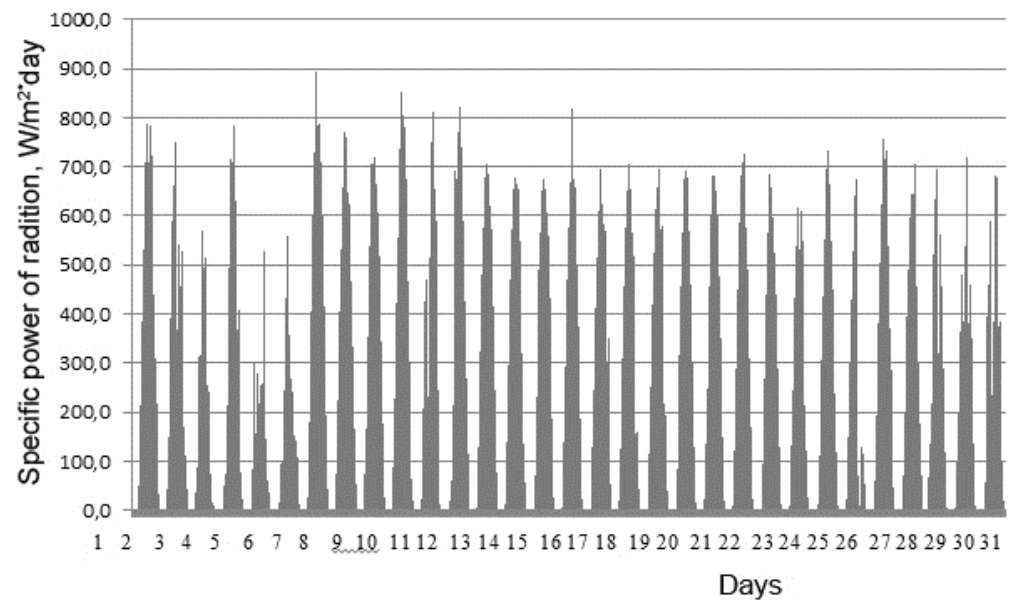

Figure 7: $\quad$ Specific power of solar radiation reception for a summer month. 


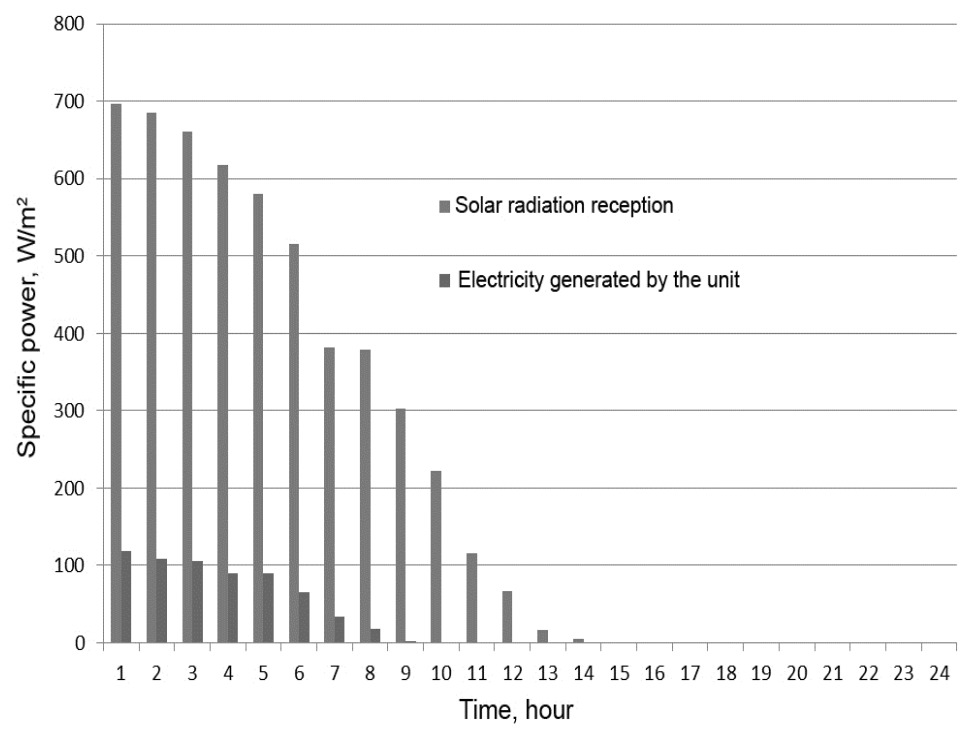

Figure 8: Specific solar energy reception and electricity generated by photoelectric unit "in duration," March 2015.

In such conditions, the efficiency of the photoelectric units has expressed statistical irregularity. Figure 9 shows the diurnal cycle power measurement data of the test photoelectric unit with the rated power of 140 watts.

Effectiveness evaluation of the photoelectric unit produced by the estimation of efficiency factor (PR-factor) method [6] calculates the daily average values in the range of $0.39-0.64$.

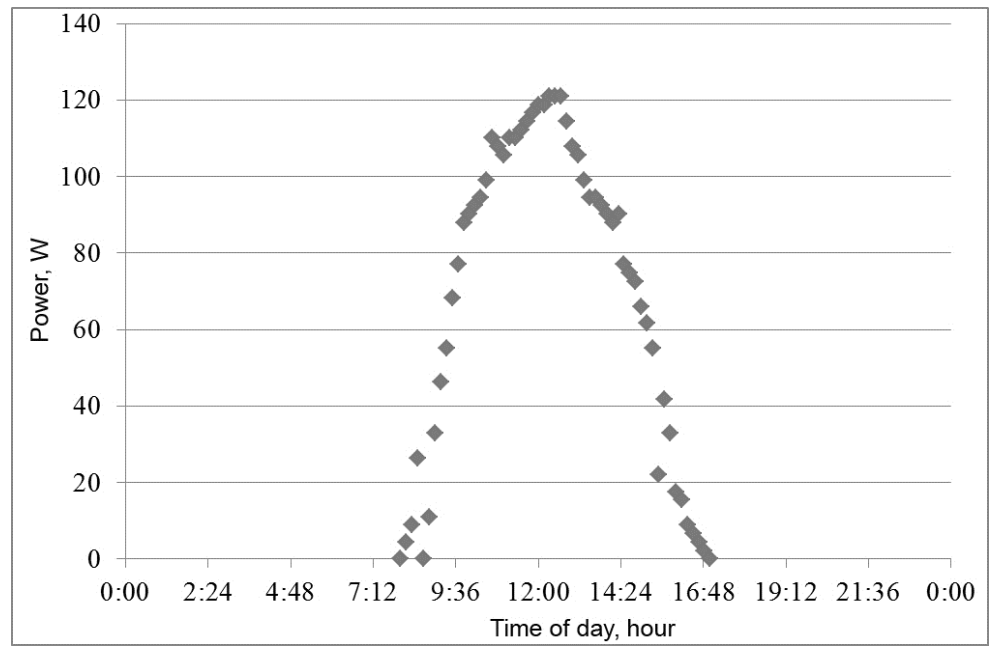

Figure 9: Power of the test PEU on hours of the day 01.04.2015. 


\subsection{Ambient temperature}

Atmospheric air temperature monitoring is subjected to considerable daily fluctuations, especially significant during winter, autumn and spring seasons. The typical daily fluctuations of temperature are shown in Figure 10.

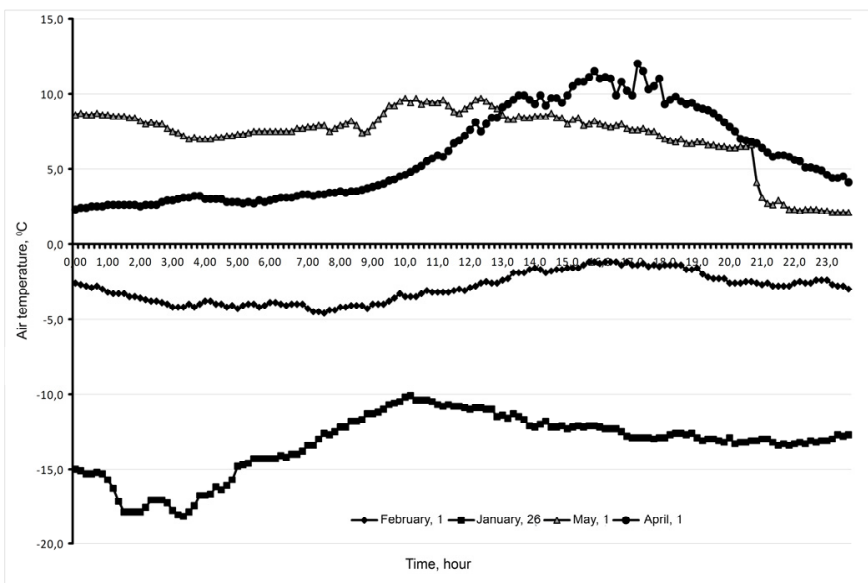

Figure 10: Typical graphs of air temperature change.

Statistical analysis of the long-term period data and comparative data on averaged monthly temperatures for several Russian cities are shown in Figure 11 .

The received data points to the cyclical nature of the average temperature change with significantly lower rates and the amplitude of annual changes for areas with an extreme continental climate.

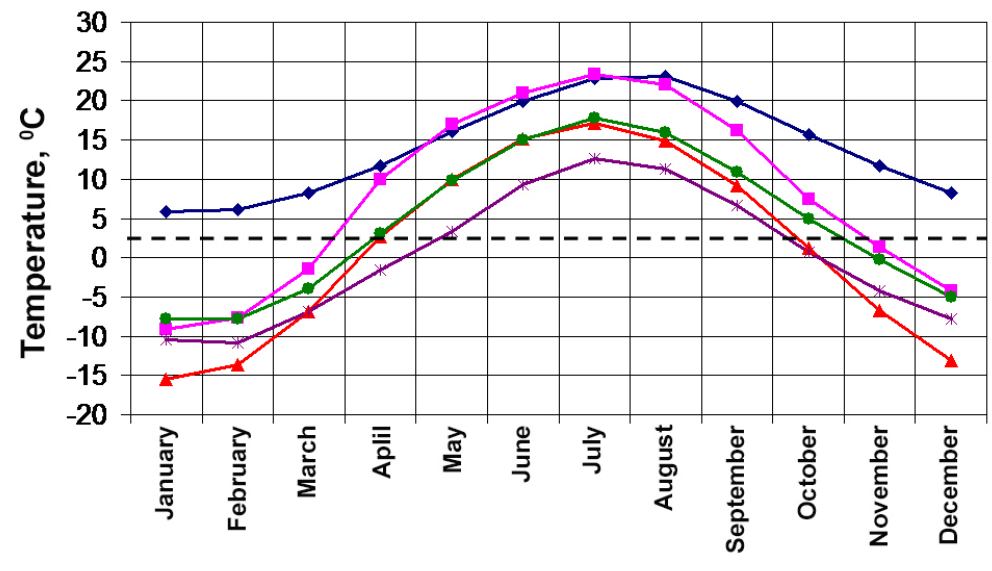

$\rightarrow$ Sochi $\rightarrow$ - Volgograd $\neq$ Yekaterinburg $\rightarrow$ Saint-Petersburg * Murmansk

Figure 11: Change in average monthly air temperature. 


\subsection{Stochasticity of electric power consumption schedules}

Along with monitoring renewable energy reception and environmental characteristics, a study about the stochastic characteristics of the power consumption graphs was conducted. Figures 12-13 show typical power consumption graphs of a separate office building with long-term (Fig. 12) and the daily cycle (Fig. 13).

The results indicate seasonal and daily irregularity of energy consumption characterized by the statistical nature of change.

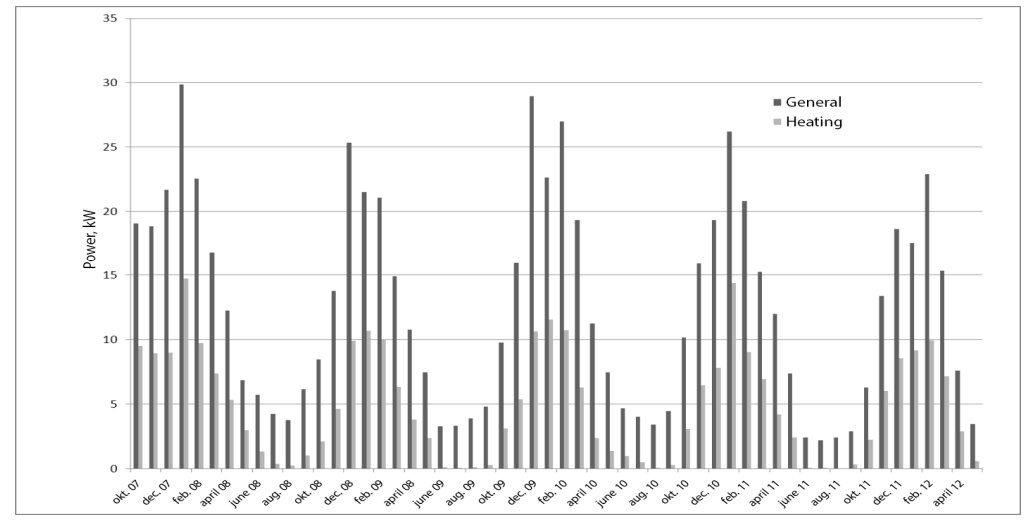

Figure 12: Graph of electricity consumption changes (5 year cycle).

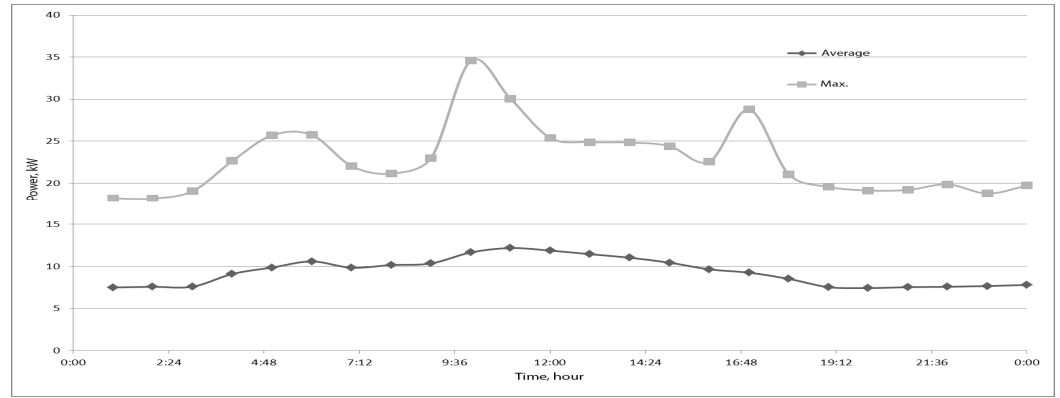

Figure 13: Daily consumption of electricity.

\subsection{Results discussion}

The results of long-term and instant characteristics of solar radiation reception, ambient temperature and power consumption monitoring reveal some common patterns:

- the expressed seasonal nature of the mentioned characteristics changes with minimal (solar radiation, temperature) and maximal energy consumption in winter; 
- high solar radiation reception and ambient temperature, with minimal energy demand in summer;

- expressed stochastic nature of the change of the instantaneous values of all mentioned characteristics with a high dispersion level.

To ensure a reliable power supply for consumers from renewable energy units, a power output should be estimated on a required level. Assuming that the load curve of the solar power unit, characterized by a constant value of daily energy requirement is $E_{n}$, we define the probability when the operating capacity of the power unit will be sufficient to cover the load as the following:

$$
Z(n)=P\left[E(n) \geq E_{u}\right]=\int_{E_{u}}^{\infty} f\left(E, M_{P E C}(n), \sigma_{P E C}(n)\right) d E=\frac{1}{2} \cdot\left(1+e r f\left(\frac{M_{P E C}(n)-E_{n}}{\sqrt{2} \cdot \sigma_{P E C}(n)}\right)\right)
$$

where $\operatorname{erf}(x)$ - is an error function.

$M_{P E C}(n), \sigma_{P E C}(n)$ - average value and mean-square deviation of the daily energy power generated by the solar unit, defined by the corresponding characteristics $M_{Q}(n)$ и $\sigma_{Q}(n)$, angle of inclination, efficiency and the total area of solar energy converters. From these curves it is understood that $Z(n)$ is at maximum during the most energy intensive period of the year when the total daily solar radiation is minimal. Integral power security can be determined according to the formula:

$$
Z=\frac{1}{T} \int_{-\frac{T}{2}}^{\frac{T}{2}} Z(n) d n=\frac{1}{2 \cdot T} \int_{-\frac{T}{2}}^{\frac{T}{2}}\left(1+e r f\left(\frac{M_{P E C}(n)-E_{n}}{\sqrt{2} \cdot \sigma_{P E C}(n)}\right)\right) d n
$$

\section{Conclusion}

1. A multi-channel, multi-parameter, high-speed, distributed in space computer monitoring system of energy reception from different renewable sources was developed and put into operation.

2. Experimental studies of solar energy reception, ambient air temperature, heat and electricity consumption during long-term, monthly and daily cycles.

3. The experimental results indicate the possibility of power supply, in climatic zones with an extreme continental climate, without the traditional energy sources usage during summer.

4. The principal importance of the small discretization periods and sufficient sample volume usage for acquisition of probabilistic estimates of studied statistical parameters was shown. 


\section{Acknowledgement}

This research is funded by the Russian Scientific Fund (Research Project 15-1930001).

\section{References}

[1] Research and applied climate handbook of the USSR: Series 3, Part 1-6, Issue 9. Perm, Sverdlovsk, Chelyabinsk, Kurgan regions, Bashkir ASSR. Leningrad: Gidrometeoizdat, 1990.

[2] Pogonin A.O. Formation principles of autonomous residential buildings in the extreme nature conditions Thesis for the candidate degree of architecture in the specialty "Architecture of buildings and structures". M.2010 p. 137.

[3] Shcheklein S., Nemikhin, Iu., Nevyantsev S., Korzhavin S., Remote monitoring complex of renewable energy units via the Wi-Fi channels and elements of artificial vision. WIT Transactions on Ecology and The Environment. Volume 2, 2014. S. 1185-1194.

[4] Nemkov D., Nemikhin Iu., Shcheklein S., Research of the renewable energy sources characteristics with the high-speed computer monitoring system National Instruments usage. XIII International Research and Practice Conference "Engineering and Scientific Applications based on National Instruments technologies" Moscow. November 19-20, 2014, DMK Press. pp. 163-165.

[5] NASA Langley Atmospheric Sciences Data Center (Distributed Active Archive Center)/ http://eosweb.larc.nasa.gov/

[6] Jailany A., Nemikhin Iu., Shcheklein S., Research of the photoelectric unit of low power productivity in the climatic conditions of Yekaterinburg. Energy and resource efficiency of low-stored residential buildings: Material of International Scientific Conference, Novosibirsk, March 24-26 2015 Novosibirsk: Publishing House of the Institute of Thermophysics SB RAS, 2015, pp. 203-207. 